Portland State University

PDXScholar

$5-25-2018$

\title{
Agroecology in Argentina: Transitioning Farmers to Resilient Agriculture
}

Ashley D. Kunesh

Portland State University

Follow this and additional works at: https://pdxscholar.library.pdx.edu/honorstheses

\section{Let us know how access to this document benefits you.}

\section{Recommended Citation}

Kunesh, Ashley D., "Agroecology in Argentina: Transitioning Farmers to Resilient Agriculture" (2018). University Honors Theses. Paper 549.

https://doi.org/10.15760/honors.555

This Thesis is brought to you for free and open access. It has been accepted for inclusion in University Honors Theses by an authorized administrator of PDXScholar. Please contact us if we can make this document more accessible: pdxscholar@pdx.edu. 


\title{
AGROECOLOGY IN ARGENTINA: \\ TRANSITIONING FARMERS TO RESILIENT AGRICULTURE
}

by

Ashley D. Kunesh

AN UNDERGRADUATE HONORS THESIS SUBMITTED IN PARTIAL FULFILLMENT OF THE REQUIREMENTS FOR THE DEGREE OF

\author{
BACHELOR OF SCIENCE \\ in \\ UNIVERSITY HONORS \\ AND \\ BIOLOGY
}

THESIS ADVISOR

DR. LEOPOLDO RODRIGUEZ

PORTLAND STATE UNIVERSITY

(2018) 


\begin{abstract}
In the context of the ecological crisis that our planet currently faces under the threat of climate change, agroecology is becoming a pertinent solution in the scientific community as a resilient approach to agricultural production. Despite vast evidence of the benefits it is not widely promoted by government and NGOs. This paper seeks to address the gap of knowledge in understanding how to help producers transition to agroecological practices with a case study in Argentina, a country with diverse eco-regions where industrial-agriculture is dominant. We identify key motivations and obstacles to adopt agroecological practices and assessed possible strategies for moving forward. Also, we explore existing knowledge that demonstrates how agroecological practices enhance the resiliency of agroecosystems. The relative effectiveness of a transition to agroecology will likely determine how well agricultural systems will be able to adapt to climate change.
\end{abstract}




\section{Preface}

This research required the approval of the PSU International Review Board of Ethics and Human Research. Unpublished data gathered through interviews was used for this research. The interviews were carried out in February, 2018. A procedure for using this unpublished information was approved on January 30, 2018, as a behavioral study of minimal risk; certificate ID: 174426.

\section{Acknowledgements}

First, and most importantly, I would like to thank Dr. Leopoldo Rodriguez my Advisor from the Department of International and Global Studies (Portland State University) for his support, motivation, fieldwork assistance and knowledge, and for his useful feedback and suggestions. I am thankful for his help facilitating interviews in Argentina and providing invaluable assistance in the preparation of this paper. Special thanks to all of my interviewees who kindly contributed to this research and made the key findings possible. I would also like to thank my colleagues from the Honors University, especially Megan Jessup-Varnum, for useful discussion and advice in the completion of my thesis. 


\section{Introduction}

\subsection{Agroecology in Argentina}

Today, global environmental change poses risks to biodiversity, agriculture, and human livelihoods. As the world population reaches its carrying capacity, and the need for food and shelter increases, land degradation worsens. The scale of these changes, specifically land degradation, is directly affecting the planet's ability to sustain ecosystem services such as food production and climate stability (Foley et. al. 2005). Given the predicted future of climate change, agroecology has emerged as a robust and crucial path toward restoring land and conserving biodiversity. Agroecology is the application of ecology to agriculture integrating studies from the disciplines of agronomy, ecology, economics, and sociology. The inherent design of the agroecological model seeks to mimic the complex, interconnected, and productive ecosystems observed in nature. By promoting stability through diversity of species, agroecology is providing the scientific and methodological basis for creating resilient agricultural systems and thus sustained potential of human opportunity (Altieri, 2011). Agroecology draws on both natural and social sciences, providing a comprehensive solution to environmental issues.

Previous research in the biological sciences has looked at biodiversity and land degradation while studies in the social sciences have investigated economic implications and food security. A holistic framework and an interdisciplinary perspective is needed to address the pitfalls of our current global food system to better understand the interconnections between social and ecological systems. In this paper we aim to understand how to encourage and better meet the needs of producers in Argentina to transition to agroecology and achieve greater resilience to the vulnerabilities of climate change.

The farming landscapes of Argentina harbor a considerable share of Earth's richest biodiversity. While it needs to be protected, there is also an acute need to provide food and well-being to the local people. Argentina was selected as a case study due to its diverse ecological regions, characteristic socio-economic inequalities, and the increasing land degradation. This study explores the scope of transitioning producers in Argentina to agroecology by answering the 
following questions: (1) What are the specific factors that motivate producers to adopt agroecological practices? (2) What obstacles do producers face when transitioning to agroecological practices? (3) What incentives and support do producers require to overcome these obstacles? In order to answer these questions, we interviewed key informants from a variety of backgrounds in the agricultural sector of Argentina. The objective of this research is to conceive adaptive strategies that thereby support producers transition to a resilient model of agriculture.

\subsection{Methodology}

\section{i) Field Methods}

We collected information using semi-structured interviews which were digitally recorded and transcribed from Spanish to English. Due to long distances in Argentina some interviews were completed by phone or email. Participants were chosen as experts and practitioners of agroecology with the assistance of Dr. Leopoldo Rodriguez (Department of International and Global Studies-Portland State University) and Dr. Valeria Soledad Faggioli (Instituto Nacional de Tecnología Agropecuaria- Córdoba). Efforts were made to ensure variability in the representation of experts in the agroecological sector of Argentina. In total, we conducted fifteen interviews, eight were face-to-face, four were by telephone, and three were done by email. Eleven of the interviewees were agronomists who specialize in agroecology and work in the field with producers. Of the agronomists, six are employees of Instituto Nacional de Tecnología Agropecuaria (INTA)- a government organization that generates and disseminates knowledge on agricultural practices suitable for the diversity of production types for the different eco-regions in Argentina. Another one of the agronomists is an academic who teaches agroecology at the Universidad Nacional de La Plata (UNLP). One works with the Union de Trabajadores de la Tierra (UTT) and three work independently for producers. Two of the interviewees are producers, one a group of Bolivian families that lease land for production and the other a small scale producer. One informant is a government administrator, President of the Servicio Nacional de Sanidad y Calidad Agroalimentaria (SENASA), and one other a NGO administrator, Specialist in Organic Agriculture at Instituto Interamericano de Cooperación para la Agricultura 
(XIGO). Producers were interviewed onsite at farms and other face-to-face interviews were conducted at the offices of the experts.

ii) Data Analysis

Qualitative analysis was performed through interpretation of the transcription of interviews. The contents were deconstructed and systematically analyzed to choose themes to compare and contrast. We focused on the relationships of the chosen themes and how characteristics of the data accounted for the existence of certain variables and the absence of others. To access what producers determined to be their main motivations and obstacles we identified patterns and variations within the dataset. First, data was organized into five main analytic categories (1) scale, (2) motivations, (3) obstacles, (4) objectives, (5) strategies. We believed these categories to be pertinent in the Argentine context due to the overall variance in responses. We found respondents made specific distinctions as to whether the production was intensive or extensive cultivation, pointing out that differences in scale and crop presented different challenges for a transition to agroecology. Secondly, we made comparisons of the different categories according to the producer's scale and tenancy. Scale was identified through criteria based on the agronomists from INTA. Four scales and tenancy were used for the purpose of this study: (1) landless, (2) small, (3) medium, (4) large. Small scale production is defined as land area less than 10 hectares. Landless production is small scale, but in addition the land is leased. Medium scale is when land cultivated is between 200-500 hectares and large scale production is greater than 500 hectares. This criterion is specific to agricultural producers. Finally, we made interpretations in order to construct a framework to provide viable strategies for the successful transition to agroecological practices.

\section{Background}

\subsection{Effects of Climate Change on Agriculture}

A vast proportion of the earth's land surface has been modified for human use in agricultural production. "Together, croplands and pastures, have become one of the largest terrestrial biomes 
occupying nearly half of the planet's land surface" (Foley et al. 2005). During the past century agricultural production has undergone profound changes. The primary changes have been to intensify food production through industrial agriculture with its use of high-yielding crop varieties, fertilization, irrigation, and pesticides. This massive expansion and intensification of agriculture is widely recognized as one of the most predominant human alterations to the global environment. "During the past 40 years, there has been a 700\% increase in global fertilizer use and a 70\% increase in irrigated cropland area" (Matson et al, 1997). As so much research has shown, while these trends have aggregately increased crop yields, they also have increased social injustice, environmental degradation, and food insecurity.

A major challenge facing the world today is how we will feed a 21 st century population of an estimated nine billion by the year 2050. Experts suggest that there is a pressing need to increase agricultural production two to three times the current range through land conversion. However, this expansion of industrial agriculture would have a devastating effect on the world's remaining biodiversity and the ecosystem services it provides (Dalgaard et al, 2003). It is now clear that agricultural expansion and intensification can have negative local and global consequences, including impacts on atmospheric constituents and climate (Matson et al, 1997). As the pressures on the biosphere increase, land use and the rising global population presents us with a dilemma.

Diverse, severe, and location-specific impacts on agricultural production are anticipated with climate change. The last IPCC report indicates that the rise of $\mathrm{CO}_{2}$ and associated "greenhouse" gases could lead to a 1.4 to $5.8^{\circ} \mathrm{C}$ increase in global surface temperatures, with subsequent consequences on precipitation frequency and amounts. Temperature and water availability remain key factors in determining crop growth and productivity; predicted changes in these factors will lead to reduced crop yields. Climate-induced changes in insect pest, pathogen and weed population dynamics and invasiveness could compound such effects. Undoubtedly, climate- and weather-induced instability will affect levels of and access to food supply, altering social and economic stability (Altieri et al, 2015).

Extensive modification of the planet's ecosystems from land conversion and agricultural intensification both is exacerbated by and contributes to climate change. Research has 
demonstrated that environmental impacts from modern agricultural land use practices play a critical role in changing the global carbon cycle. It is estimated that approximately $35 \%$ of anthropogenic $\mathrm{CO}_{2}$ emissions derive directly from land use, while industrial monoculture agriculture encompasses $80 \%$ of the 1.5 billion hectares of arable land which due to its homogeneity is particularly vulnerable to climate change (Foley et al, 2005; Altieri et al, 2015). As a result, there is mounting concern about the complex environmental and social consequences from industrial agriculture and how climate change could increase the severity of these impacts.

\subsection{Agroecology as a Model for Resilience}

Folke's definition of agriculture resiliency comprises diversity of species, human opportunity, and economic options. For social-environmental systems, resiliency is related to $(a)$ the magnitude of shock that the system can absorb and remain within a given state; $(b)$ the degree to which the system is capable of self-organization; and $(c)$ the degree to which the system can build capacity for learning and adaptation. "In general, resilience derives from things that can be restored only slowly, such as reservoirs of soil nutrients, heterogeneity of ecosystems on a landscape, or a variety of genotypes and species" (Folke et al, 2002). The configuration of agroecological design lends itself to achieve these necessary elements which align well with Folke's definition of resiliency. If resiliency is the goal, then the path toward its successful attainment seems to hinge on a cohesive interdependence between the complex "component parts" of any given agroecosystem.

Ecological theory posits that the overall resilience of a social-environmental system is not simply the sum of the capacities and vulnerabilities of its component parts, but rather is manifest in the dynamic and non-linear interaction between the values, incentives and institutions that structure human behavior and the implications of behavior for the factors that regulate the function of the broader system (Eakin \& Wehbe, 2008). 
To strengthen the resilience of agroecosystems adaptive management performs a critical role. The future severity of climate change impacts on agricultural production will highly depend on the kinds of adaptation strategies used. Minor modifications to monoculture agriculture will only temporarily alleviate negative impacts. The most enduring benefits will likely result through strategies derived from the discipline of agroecology (Altieri et al, 2015).

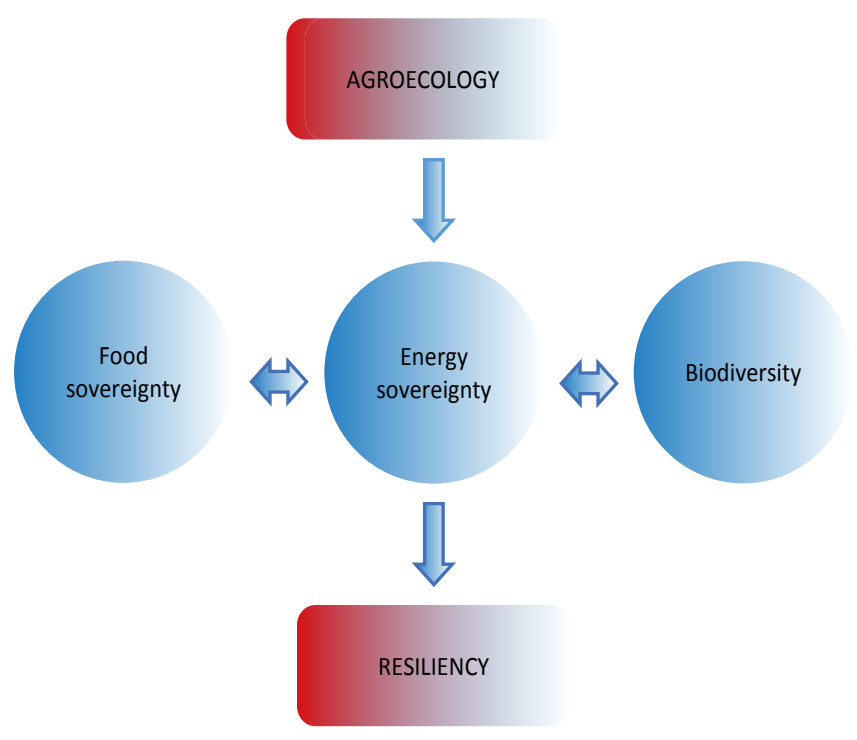

Fig. 1 Agroecology and resiliency model adapted from (Altieri \& Toledo, 2011)

Agroecology draws upon basic ecological principles that provide the conceptual framework. This ecosystem view of agriculture studies the interactions between plants, animals, humans and the environment within an agroecosystem (Dalgaard et al, 2003). Agroecological farming methods differ from conventional farming because its primary aim is sustainability, not productivity, and it encompasses the complex interconnections among the farmed land, its surrounding environment, and the human community. As a result, illustrated in Fig. 1, agroecology-based production systems are biodiverse, energetically efficient, and comprise the basis of a productive food-sovereignty strategy (Altieri, 2011). Agroecology has the explicit goal to create a sustainable food system that is ecologically sound, economically viable, and socially just.

Agroecological practices support food sovereignty by enabling farmers to boost and diversify their production, stabilize yields and decrease dependency on expensive and often hard-to-access inputs. The benefits of scaling up agroecology across the landscape include greater agrobiodiversity, lower 
environmental impact, improved landscape stewardship and increased climate resilience (Silici, 2014).

Agroecology promotes resiliency through diversity of species and human opportunities, furthermore, it recognizes that human activities are not separate from the environment but are interconnected parts of the same system. Thus, as a discipline, agroecology is more integrative and less reductionist (Dalgaard et al, 2003). Ecologist Daniel Janzen was one of the first to formalize this ecosystem-view of agriculture with his work in 1973. In his vision, productive ecosystems should be grounded in local ecological knowledge, locally adapted, limited by local environments and culture, and designed to meet local needs first rather than respond to the demands of export markets for single commodity crops (Gliessman, 2013). The ecosystem-view of a social-environmental system creates a framework that is better able to adapt and resist the rising effects of climate change. Agroecological strategies, such as organic soil management, water conservation, and general enhancement of biodiversity, demonstrate resilience because of its complexity and adaptive capacity. Previous studies have shown a link between higher levels of biodiversity and resiliency in agricultural systems following extreme climatic events (Altieri et al, 2015). Thus, having a greater understanding of these features that underlie the resilience of agroecology is urgent as they provide the foundation for the design of sustainable agriculture. Contrary to industrial agriculture, the integration of greater diversity, as demonstrated in agroecology, increases resilience against climate-related variability. "Biodiversity of species acts as a buffer against failure due to environmental fluctuations, by enhancing the compensation capacity of the agroecosystem, because if one species fails, others can play their role, leading to more predictable aggregate community responses or ecosystem properties" (Altieri et al, 2015). The agroecology framework is able to promote resiliency and mitigate against environmental and climatic uncertainty by working with and not against nature and maintaining crop diversity. 


\subsection{The Study Region}

This study focuses on Argentina, a country that hosts one of the most widespread ecosystem varieties on the planet including fifteen continental zones, three oceanic zones, and the Antarctic region. As a result of such ecosystem variety, Argentina has among the world's largest extent of biodiversity (“Argentina-Main Detail,” 2013). The country faces environmental problems associated with agricultural expansion and intensification. At the current rate of agricultural expansion and intensification, it is estimated that Argentina's agricultural soils will be exhausted in the next 50 years (Eakin \& Wehbe, 2008). According to government reports, soybean production contributed to 1.7 million acres of lost native forest in just one decade. Deforestation continues in the presence of agriculture expansion which is estimated at nearly 250,000 hectares a year (Lagpegna, 2016). As a consequence, the country's rich biodiversity is under threat. The stability of Argentina's vast ecosystems will largely determine the level of resilience under the presence of climatic variability.

Argentina has a rich agricultural history, but today industrial agriculture dominates the landscape. In the early 1990s, neoliberalism took root when the government adopted policies recommended by global financial institutions that privatized public companies and eliminated import tariffs and export taxes. Family farms tried to adapt to the new model focused on export commodities, and took on huge debts leading one-fifth of existing farms to go out of business. The neoliberalization of agriculture severely changed the shape of agro-industries and the social environment. As policies oriented agricultural production toward globalization and export commodities, small producers-once a central part of regional development efforts-became marginalized. Agriculture policies paved the way for the adoption of capital-intensive technology (inputs and machinery). Toward the end of the decade, the agricultural environment of Argentina was further altered with the approval of genetically modified crops. At present, genetically modified crops cover over 50\% of the country's arable land (Lagpegna, 2016). A USDA report stated that "No other Latin American country embraced Genetically Modified Crops as wholeheartedly as Argentina." In the 2000s, giant multinational agribusinesses began to dominate Argentina's landscape leading to rampant deforestation, soil depletion, and dumping of glyphosates and other agrotoxics in the ecosystems (Lagpegna, 2016). This type of agricultural expansion and intensification ensues considerable environmental and social consequences. 
Climatic conditions around the globe have been shifting. Frost, droughts and floods have affected not only the production of individual households but also the regional economy. These observed trends are in line with climate change scenarios. The region is likely to experience increasing temperatures and precipitation, particularly during the southern hemisphere summer (DecemberFebruary) and fall (March-May), while decreasing precipitation is projected for winter (June-August). An expected increase in climatic variability and wind and water erosion are likely to constitute an increasing threat to agricultural production in the future where different climate extremes may occur during a single crop cycle or year. Collectively these processes are enabling shifts in land tenure, cropping patterns and technology use while raising concerns over the social and ecological sustainability of the region's agroecosystem (Eakin \& Wehbe, 2008).

In the Argentinean case, globalization forces redefined the country's agricultural sector by making it export-oriented. The agro-export model brought with it a variety of economic, environmental, and social problems. "The growing push toward industrialization and globalization with its emphasis on export crops are increasingly reshaping the region's agriculture and food supply, with yet unknown economic, social, and ecological impacts and risks" (Altieri \& Toledo, 2011). Humans rely on the ecosystem services that intact ecosystems provide for their survival and industrial agriculture directly threatens this balance. The risks industrial agriculture pose to social-environmental systems are pervasive. Building social and ecological resiliency under the threat of climate change is of key importance. In order to address these uncertainties and promote adaptive capacity this study seeks to understand what motivates producers to transition to agroecology, what obstacles need to be overcome, and how to best support a transition.

\subsection{Research Focus}

Land conversion and intensification practices overburden the ecological integrity that we rely on. With the addition of uncertainties posed by global environmental change, it is increasingly 
important to address the resiliency of our food production systems. "The effects of rising temperatures and more extreme weather events will constitute a major threat to food security and especially hurt rural farmers" (Sunderland, 2011). Industrial agriculture could have a continuing devastating effect on the world's remaining biodiversity while increasing environmental degradation, food insecurity, and social injustice.

Adopting agroecological practices is the first step toward achieving greater environmental, social, and economic sustainability. In order for the planet to continue providing ecosystem services long-term the global food system requires a transformation to a more agroecological framework. In the context of Argentina, agroecology offers a promising solution to achieve greater economic dependence in the agricultural sector while ensuring adaptive capacity in communities and protecting the regions many diverse ecosystems which provide the country enhanced stability in the face of climate change.

Due to its reliance on water, temperature, and balance of atmospheric gases agricultural production is the human activity which is most vulnerable to the effects of climate change (Altieri et al, 2015). Adopting agroecological practices is an essential step that must be taken to support producers and communities to build resiliency under the threat of climate variability. There is an eminent need to understand the transition toward a sustainable food production system that contains the virtues of the above described ecosystem-view model. Active research in both biological and social sciences continue to focus on individual challenges of socialenvironmental systems. By reducing such a complex system to its "naïve" parts we continue to threaten the very food systems that sustain our existence. If we don't integratively understand the transition phase connecting individual components of an agroecosystem, then the total effectiveness of our understanding is largely limited in value. This limitation inhibits our ability to attain a working and resilient food production system able to quickly adapt to the problems generated by climate change. The study's purpose is to provide a holistic framework offering general strategies which move our food system forward toward resiliency. This integrative approach bridges a much needed gap in the disciplines of biology and sociology that are interested in conservation and food security. 


\section{Results \& Discussion}

\subsection{Motivations}

To shift agricultural production in Argentina to more sustainable farming methods we must first identify the diverse factors that influence producers' decisions to adopt them. Analysis of the interviews conducted indicate that incentives fall within four major categories: economic, environmental, health, and commercialization. We asked experts and practitioners of agroecology to discuss the reasons that drive farmers' interest to convert production to agroecology and found the most frequent reason cited had to do with breaking dependency on external inputs. This is an economic concept that directly affects the producers' livelihoods. A researcher from the University of La Plata explains that costs are reduced because no external inputs are needed in agroecology. Reducing costs of production by eliminating external inputs such as fertilizers, pesticides, seeds and energy provides an attractive economic opportunity. Bolivian farmers acknowledged that if they do not have to pay for inputs, which rise with U.S. dollar prices, they reap greater savings. The majority of experts agreed that through lower production costs producers can achieve greater income security and this is highly motivating, especially for small producers.

We also found that the decision to switch to agroecology is influenced by environmental and health factors. Experts identified these two aforementioned motivations with nearly equal relevance. Many interviewees discussed motivation as a consequence of producers' environmental awareness and concern about health. An INTA agronomist clarifies that producers recognize the damage agrochemicals have on the environment and their health and this is a motivating factor to transition to agroecology. A few participants noted that producers may have different environmental objectives but many are noticing rising health problems in their communities. Many producers have been intoxicated and they are interested in alternatives to conventional farming without the use of toxic agrochemicals. Environmental and health motivations, while not as dominate as the economic factor, must be realized. As we look toward the future of agriculture, Ricardo Luis Negri of SENASA stresses the importance of younger producers. He explains that our understanding of sustainability comes with the new generation that upholds a proud connection to an ecosystem view; a view that acknowledges a system as 
dynamic, whole and interconnected.

Commercialization opportunities provide producers another motivation to transition to agroecology. Interviewees determined that the availability of new markets, especially direct to consumer [DTC] markets, are highly attractive to producers. Selling directly to consumers is advantageous because it increases financial returns by reducing marketing costs. Producers can sell at or near retail prices by avoiding paying intermediaries. In addition, there is also an increase in value of the product due to its differentiation. While in practice this is not always true, as we will discuss in the obstacles, there is a clear opportunity to receive higher earnings than conventional products if sold with the added value from agroecology in the organic sector.

Our findings suggest that the important factors that drive producers' choices to adopt agroecological production in order of relevance are economic, environment, health, and commercialization. We further recognize that these factors which influence producers' choices are complex and variable from place to place. It is hard to generalize from smaller scale studies such as this, and results may apply only to the studies' respective area or set of circumstances.

\subsection{Obstacles}

For sustainable agriculture to be more widely adopted across Argentina it is critical to understand the constraints to transitioning to agroecological practices. We reviewed experts' views on the obstacles producers face when shifting land use practices and found six categories critical to making a successful transition. The most common obstacles encountered by producers in Argentina include: lack of knowledge, new concept, technical assistance, commercialization, labor, land, capital, production transition, and government support. We address these obstacles by describing them in the context of producers' motivations and what barriers they most frequently confront.

\section{i) Environment \& Health Obstacles}

Motivations which arise from environmental and health concerns encounter various obstacles. Specifically, lack of knowledge, new concept, and technical assistance depict some of the most significant challenges. We define lack of knowledge as an absence of technical expertise and 
general awareness. Interviewees explain how producers' traditional farming knowledge has been devalued and eroded. When municipalities create agrochemical regulations producers are left with few alternatives within the conventional model they are familiar with. The cultural erosion of traditional farming knowledge leaves producers in a position where technical assistance is needed to examine local conditions and collaborate in order to adopt appropriate methods. However, agronomists are generally trained in conventional methods and thus their capacity is limited.

New concept is defined here as a social view related to the fact that agroecology is new to the region. For example, when environmental and health awareness drives producers to seek more sustainable farming methods a barrier often encountered is that producers don't believe another way is possible. The community tells them that agroecology is not viable because in Argentina, agriculture is predominantly performed with the use of agrochemicals. This presents a challenge that takes root in the mind and can be linked to the fact that agroecology is a new concept in the region. Society's framework around conventional agriculture as a model for the future creates a barrier for producers who feel the need to conform to their neighbors' judgments. A serious conflict emerges when this is coupled with the producers' belief that they cannot farm without agrochemicals. Both lack of knowledge and new concept present themselves as obstacles due to cultural erosion, societal pressure and mentality, and agronomist capacity.

Environmental motivations also experience an obstacle that derives from the scarcity of technical assistance which we outline as a combination of education, research, and development. While there is tremendous support among scientists, research in sustainable farming is not prioritized. Not only is research and experimentation limited, but it also lacks any significant focus on agroecology. Agronomy programs in the vast majority of universities tend to exclude alternative training in sustainable agriculture. Instead the current paradigm in most universities rely heavily on the agrochemical input model. At present, there is a dearth of funding for agroecological research and a clear need for public funding.

\section{ii) Commercialization Obstacles}

Motivations driven by commercialization meet various challenges during a transition to agroecology. While agroecologically grown products can open novel pathways for new markets 
and higher prices, numerous obstacles still need to be reconciled. At present no price differentiation exists between agroecological and conventional produce, making it difficult for agroecological producers to compete. If there is an increase in demand for agroecological products, then the internal market would take a favorable turn to set higher prices. However, in this context, intermediaries serving the internal markets often inhibit the ability of agroecological producers to increase their prices because they demand homogenous produce that can only be obtained with conventional agriculture practices.

A primary challenge with gaining access to the niche organic market is certification. The certification process that exists for organics in Argentina does not exist for agroecology. Several agronomists we interviewed worked for organically certified producers who tended to be medium- to large-scale producers of extensive crops that can be sold in domestic and foreign markets at a premium price. However, agroecological small producers covered by our research were generally unwilling to engage in the lengthy and relatively costly process of acquiring organic certification. The cost of certification particularly_inhibits small_scale producers from obtaining the certification necessary to enter more profitable markets. Certification can be critical to added-value products when direct-to-consumer (DTC) markets and farmers' fairs prove to be monetarily insufficient and the sale in conventional internal markets reject product due to their varied characteristics.

\section{iii) Economic Obstacles}

Producers in Argentina are generally driven by economic factors. However, barriers such as: labor, land, capital, and the production transition can become obstacles to the successful adoption of agroecology. Labor is defined as the workforce required to sustain agricultural production and capital includes both monetary resources and infrastructure. Although costs are reduced because no external inputs are needed labor remains a pertinent issue since agroecology is more labor intensive than conventional agriculture. The scale of production and the producer's capital will likely determine whether family labor or hired labor is utilized. For example, small producers are more prone to use family labor if available, but may also hire if the economic equation is favorable and they have access to sufficient capital. 
Land plays an even larger role inhibiting producers to successfully transition to agroecology. Here land refers to any arable land capable of being ploughed and used to grow crops. Both generational divisions of farmed land and the massive expansion of soybean directly impede producers' access to land. If land becomes available, then there is also the challenge of expensive rent. When a producer needs to pay rent it is not viable to grow organically because they need a faster production cycle to meet this demand. Without long-term and inexpensive land access it does not make sense for a producer to practice agroecologically for its lasting benefits. It is a practice that is meant to become more productive and sustainable with time.

The production transition can be a huge barrier to overcome since it takes years for the land to become productive again. We define production transition as the time required for conventional land to reestablish fertility. During the transition period producers commonly experience reduced yields attributed to the time required for necessary changes in chemical, physical, and biological properties of soil. This period not only requires time, but new infrastructure and capital. Thus, although economically attractive over the long-run, transitioning to agroecology is a slow going process that requires initial support and investment for success.

All four motivations (economic, environment, health, and commercialization at some point encounter a challenge that could be managed with proper government support. At present, government policies do not tend to benefit small producers and subsidies do not go toward organic agriculture. While there is lower taxation for organic exports, this is narrowly targeted at medium- to large-scale producers. Economic financial tools to get started and manage the production transition is critical. Essentially, producers need the government to back them in order to more readily adopt agroecological practices.

\subsection{Objectives and Strategies}

A practical framework highlighting key objectives and strategies is important for the purpose of transitioning agricultural production in Argentina to agroecological practices. The recommendations below, serve as an effective tool to inform the best steps to move forward. When discussing these strategies, it is essential to acknowledge the appropriateness for each 
recommendation as determined by local conditions. Thus, broad implementation of the preceding strategies is limited by region, crop, and scale.

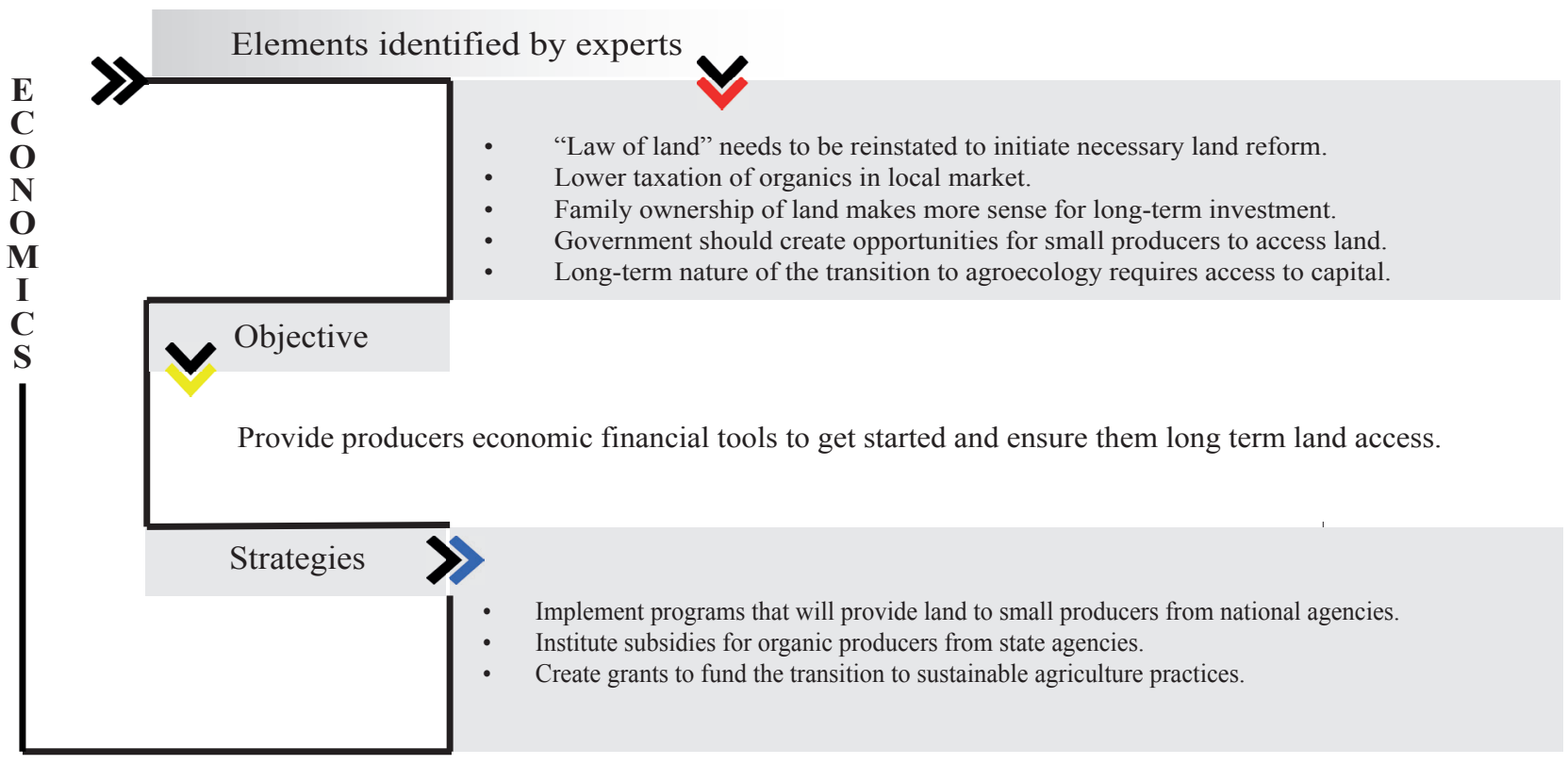

Fig. 2 Key economic factors suggested for the transition to agroecology in Argentina

Based on the information from experts in Argentina, we have identified three main objectives to transition to agroecological practices. These objectives directly address all four of the motivations: economic, environment, health, and commercialization. To address economic motivations, it is necessary to provide producers financial tools to get started and ensure them long-term land access (Fig. 2). State, national, and/or international agencies would be called on to target this objective by providing land to small producers interested in using agroecological methods and influencing access to capital for agroecological producers through subsidies and grants. In the case of Argentina, one approach to providing access to land could be through the purchase of the land by a non-profit fund, to be leased it at a low price. The land would be required to produce using agroecological methods in perpetuity. Here, it is important again to stress that for agroecology to be worthwhile, it is especially important for long term access to land and thus, non-profits must have a commitment to land contracts that extend over a relatively long amount of time. This proposed non-profit would work as a steward of land, while the producers would work with the land directly. Government subsidies and private grants are two other ways that can directly strengthen economic efforts and promote the transition to 
agroecology. Incentives such as these offer another source of capital for producers that encourages the protection and enhancement of ecosystem services. In the Argentine case, subsidies for agroecological production are very unlikely in the foreseeable future.

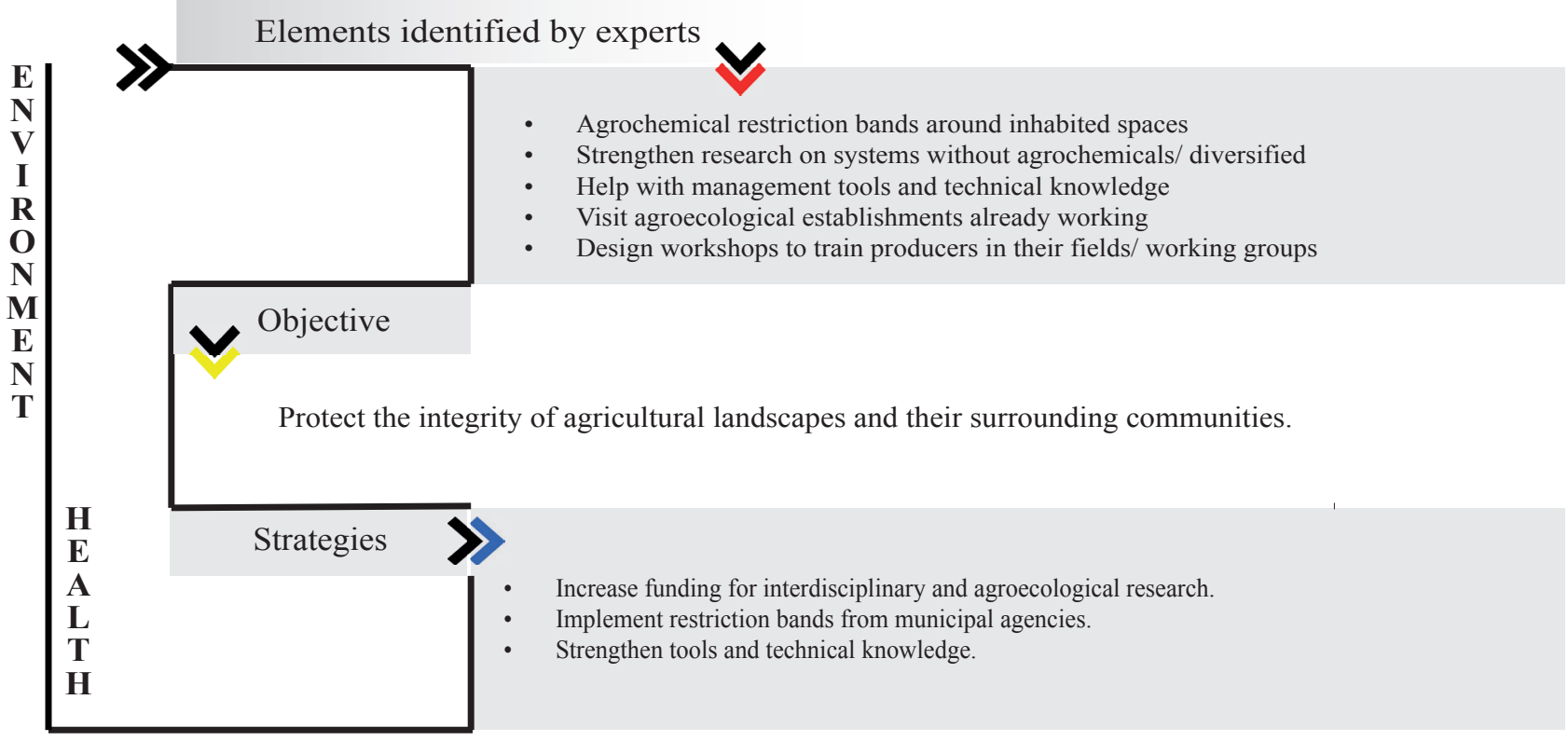

Fig. 3 Key environment and health factors suggested for the transition to agroecology in Argentina

The next objective is to protect the integrity of agricultural landscapes and their surrounding communities (Fig. 3). This approach encompasses both environment and health objectives with a focus on policy support and technical assistance. First, it is important for municipalities to provide legislative authority that prohibits the use of agrochemicals around inhabited spaces. As such, this constitution would guarantee the right to a healthy and ecologically sound environment for all. Although this is already taking affect in some areas, it is essential that implementing restrictions on agrochemicals is more widespread. A restriction on agrochemicals not only aims to protect the health of the environment and its surrounding community, but it also affords producers suitable space to implement agroecological practices. In addition, we suggest that tools and technical knowledge of agroecology need to be strengthened in universities. There is a wide disparity in public research favoring conventional agriculture compared to agroecological systems. We suggest that investment in agricultural research needs to be redirected toward applications of agroecology to address the current and future challenges facing global food systems. We consider funding from those working in the private sector who are interested in 
promoting the protection of biodiversity and livelihoods of small producers a vital source of financial support. Because agroecology is grounded in local socio-environmental conditions, tools such as hosting on site workshops and creating working groups are key approaches to promote horizontal sharing among farmers. This type of knowledge sharing is an interdisciplinary approach that combines traditional knowledge with scientific expertise. NGOs and governmental institutions play a key role in helping catalyze these strategies.

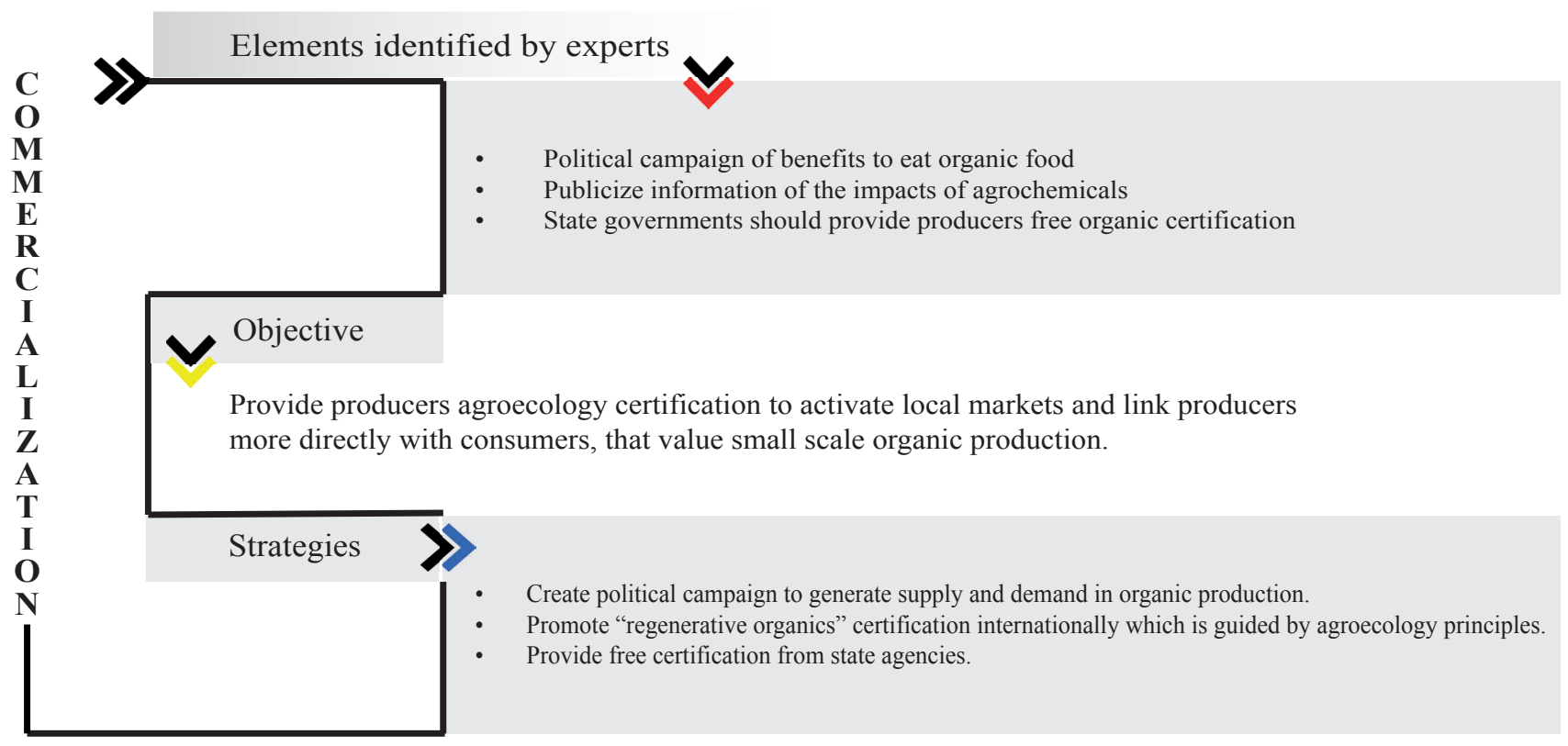

Fig. 4 Key market factors suggested for the transition to agroecology in Argentina

Finally, the last objective relates to the commercialization of products grown using agroecological methods (Fig. 4). An important element would be to provide agroecological certification in order to activate local markets and link producers more directly with consumers that value small-scale organic production. Cost of certification was an important barrier, but so was the lack of specialized outlets where their products could be sold at a higher price. At present, there is no centralized system for certifying agroecological products in Argentina. An interview participant indicates that efforts have been made to put in place peer-to-peer agroecological certification as a way to create a credible and inexpensive certification process. A system of free certification offered by the national or state governments, plus a campaign to raise regional awareness of the benefits of agroecological practices and food, would be of great value. While free certification would be initially challenging, it offers access to the niche organic 
market. There is an international certification gaining recognition that embodies elements of agroecology called "regenerative organics" that could play a role in shaping global markets. Regenerative organic certification builds upon organic certification, but also recognizes economic stability and fairness to farmers, ranchers, and workers, and the importance of creating resilient regional ecosystems and communities. We suggest free certification and the promotion of organics as a means to increase local and global commercialization opportunities. These integrative objectives and strategies address the gap of knowledge and provides a holistic framework to understand how to help producers transition to agroecological practices.

\section{Conclusion}

The present paper illustrates the motivations and obstacles producers face for transitioning to agroecological practices in Argentina. From the development of this work we can see support is needed from all levels of government, the scientific community, and society in general. We propose that for producers to successfully transition to agroecology, it is critical that municipal, state, and national government use a range of tools to support these efforts. This study offers opportunities for NGOs to create campaigns that promote organics and universities to implement agroecology into their agronomy programs. While further research is required, exploring producers'motivations to shift to agroecology and the obstacles they encounter is an important step in outlining objectives and strategies to best support producers transition to resilient farming methods. 


\section{References}

Altieri, M. A., Nicholls, C. I., Henao, A., \& Lana, M. A. (2015). Agroecology and the design of climate change resilient farming systems. Agronomy for Sustainable Development, 35(3), 869-890. doi:10.1007/s13593 015-0285-2

Altieri, M. A., \& Toledo, V. M. (2011). The agroecological revolution in Latin America: rescuing nature, ensuring food sovereignty and empowering peasants. Journal of Peasant Studies, 38(3), 587-612. doi:10.1080/03066150.2011.582947

"Argentina-Main Details". Montreal, Canada: Convention on Biological Diversity. 2013. Retrieved April 12, 2018, from https://www.cbd.int/countries/profile/country=ar

Dalgaard, T., Hutchings, N.J., \& Porter, J.R. (2003). Agroecology, scaling and interdisciplinarity, Agriculture ,Ecosystems \& Environment, 100 (1), 39-51. doi: 10.1016/s01678809(03)00152-x

Eakin, H.C., \& Wehbe, M.B. (2008). Linking local vulnerability to system sustainability in a resilience framework: two cases from Latin America. Climatic Change, 93(3-4), 355377. doi:10.1007/s10584-008-9514-X

Foley, J., DeFries, R., Asner, G., Barford, C., Bonan, G., Carpenter, S., Snyder, P. (2005). Global Consequences of Land Use. Science, 309(5734), 570-574. Retrieved from http://www.jstor.org.proxy.lib.pdx.edu/stable/3842335

Folke, C., Carpenter, S., Elmqvist, T., Gunderson, L., Holling, C., \& Walker, B. (2002). Resilience and Sustainable Development: Building Adaptive Capacity in a World of Transformations. AMBIO: A Journal of the Human Environment, 31(5), 437. doi:10.1639/0044-7447(2002)031[0437:rasdba]2.0.co;2

Gliessman, S. (2013). Agroecology: Growing the roots of resistance. Journal of Sustainable Agriculture, 37(1), 19.

Lagpegna, P. (2016). Soybeans and power genetically modified crops, environmental politics, and social movements in Argentina. New York: Oxford University Press.

Matson, P., Parton, W., Power, A., \& Swift, M. (1997). Agricultural Intensification and Ecosystem Properties. Science, 277(5325), 504-509.

Silici, Laura. (2014). Agroecology: What it is and what it has to offer. IIED Issue Paper. IIED, London. Product code: 14629IIED

Sunderland, T. (2011). Food security: why is biodiversity important? International Forestry Review, 13(3), pp.265-274. 


\section{Appendix}

\section{Definitions}

Adaptive capacity:

The ability to buffer change and allow for learning and development (Folke et al, 2002).

Agroecology:

The application of ecology within agriculture that covers integrative studies of agronomy, ecology, and sociology which studies the interactions between plants, animals, humans and the environment within agricultural systems (Dalgaard et al, 2003). Agroecology-based production systems are biodiverse, resilient, energetically efficient, socially just and comprise the basis of an energy, productive and food sovereignty strategy (Altieri, 2011).

\section{Agroecosystem:}

The agro-ecosystem represents the interaction of ecological, technological and socio- economic factors (Silici, 2014).

Carrying capacity:

Carrying capacity is the maximum population size an environment can support based on water, food, habitat, etc. The number of humans the earth can support has emerged as an eminent concern of the $21^{\text {st }}$ century. Carrying capacity describes the limits to these life-sustaining resources that the Earth can provide us.

Ecosystem services:

Examples of ecosystem services include biodiversity; soil and water quality; nutrient management (nitrogen fixation); soil water-holding capacity; control of weeds, diseases, and pests; pollination services; carbon sequestration; energy efficiency and reduction of atmospheric warming potential; resistance and resilience to climate change; and crop productivity (Silici, 2014).

Food sovereignty:

The right of peoples to healthy and culturally appropriate food produced through ecologically sound and sustainable methods, and their right to define their own food and agriculture systems. Food sovereignty uses the contributions of nature in diverse, low external input agro-ecological production and harvesting methods that maximize the contribution of ecosystems and improve resilience and adaptation, especially in the face of climate change (Silici, 2014). 
Industrial agriculture:

Industrial agriculture works with resources that do not grow back, is energy intensive, relies heavily on capitalist technology (agro-toxics, GM seeds, heavy machinery), and is of monoculture design. The primary focus of industrial agriculture is to meet crop needs through environmental modification and agricultural inputs causing tremendous social and ecological havoc all over the world (Gliessman, 2013).

Resilience:

Resilience is often associated with diversity — of species, of human opportunity, and of economic options - that maintains and encourages both adaptation and learning. For social-ecological systems, it is related to $(i)$ the magnitude of shock that the system can absorb and remain within a given state; (ii) the degree to which the system is capable of self-organization; and (iii) the degree to which the system can build capacity for learning and adaptation (Folke et al, 2002).

Sustainability:

Sustainability is the capacity to meet the needs of the present without compromising the ability of future generations to meet their own needs. There are three interconnected components of sustainability that describe the relationships between the environment, social, and economic aspects of our world.

\section{Interview questions}

1. What are the major crops grown agroecologically in Argentina?

2. Are these agroecological crops mostly grown for subsistence, local markets, or export?

3. What major obstacles and socio-economic challenges do small farmers face in Argentina?

4. How would agroecological practices help confront these challenges?

5. What percentage of farms practice agroecology in Argentina?

6. What are the major obstacles that inhibit farms from transitioning to agroecological practices?

7. What tools are critical in order to encourage small producers to adopt agroecological methods?

8. What organizations or initiatives exist in Argentina that promote agroecology?

9. Does the government promote agroecological practices in Argentina? If so, what sort of programs are in place and 
through which agencies?

10. Is government support important or necessary to help small producers successfully transition to agroecological practices?

11. What is the primary motivation for small producers to learn and apply agroecological methods?

12. How do you believe agroecological methods are best learned by small producers?

13. Have you seen any successful transitions to agroecological practices and if so what is the greatest success?

14. Likewise, what was the biggest disappointment?

15. What is the main area in which support is needed?

16. Are there any factors that make Argentina's specific situation unique in the context of the movement toward transitioning to agroecological methods on a global scale? 